\title{
EFFECT OF WATER ABSORPTION ON THE MECHANICAL PROPERTIES OF FLAX FIBER REINFORCED EPOXY COMPOSITES
}

\author{
Umit Huner $^{1}$ \\ 1 Faculty of Engineering, Department of Mechanical Engineering, Trakya University, Edirne 22030, Turkey, \\ e-mail: umithuner@trakya.edu.tr
}

Received: 2015.04.02

Accepted: 2015.05.08

Published: 2015.06.01

\begin{abstract}
Flax fiber reinforced epoxy composites were subjected to water immersion tests in order to study the effects of water absorption on the mechanical properties. Epoxy composites specimens containing 0,1,5 and 10\% fiber weight were prepared. Water absorption tests were conducted by immersing specimens in a de-ionized water bath at $25^{\circ} \mathrm{C}$ and $90{ }^{\circ} \mathrm{C}$ for different time durations. The tensile and flexural properties of water immersed specimens subjected to both aging conditions were evaluated and compared alongside dry composite specimens. The percentage of moisture uptake increased as the fiber volume fraction increased due to the high cellulose content. The tensile and flexural properties of reinforced epoxy specimens were found to decrease with increase in percentage moisture uptake. Moisture induced degradation of composite samples was significant at elevated temperature.
\end{abstract}

Keyword: natural fiber, mechanical properties, epoxy composites.

\section{INTRODUCTION}

Various lignocellulosic fillers (Table 1) can be used (flax, hemp, kenaf, sisal, jute) whose physical properties such as density, tensile strength, modulus of elasticity, etc. are related to the internal structure and chemical composition of fibers [1].

In recent years, the use of flax fibers as reinforcement in composites has gained popularity due to an increasing requirement for developing sustainable materials. Flax fibers are cost effective and offer specific mechanical properties comparable to those of synthetic fillers. Composites made of flax fibers with thermoplastic, thermoset, and biodegradable matrices have exhibited good mechanical properties [2]. Disadvantages of these materials are high moisture absorption capacity. It has been long known that epoxy and epoxy composites easily absorb water when exposed to humid environments. This reduces the stable lifetime of the material. Experiments show that the water in epoxy is present in two states [2]; firstly, distributed water molecules between the polymer chain and condensed water in fractures and cavities. Lignocellulose natural fibers are highly hydrophilic due to the presence of an $\mathrm{OH}$ group. The incorporation of these fibers into the matrix increases water uptake of the composites by forming a hydrogen bond between water hydroxyl groups of cellulose, hemicellulose, and lignin [3]. The hydrophilic character of natural fibers leads to low compatibility with hydrophobic polymer matrices and also to a poor dimensional stability as water uptake swells fibers [3].

The alternative of natural fibers as a reinforcing material in polymer composite materials is still attracting much interest at both the academic and industrial level. Currently, various researchers and material scientists all over the world are focusing their attention on effective utilization of these natural fibers in polymer composites.

Anter et al. [4] have reported the effect of water absorption on hardness properties for Epoxy reinforced with glass fibers in their research article. They used the Epoxy resin as matrix re- 
Table 1. A comparison between the physical properties of selected natural fibers [5-8]

\begin{tabular}{|c|c|c|c|c|}
\hline Fibre & Density $\left(\mathrm{g} \cdot \mathrm{cm}^{-3}\right)$ & Tensile strength $(\mathrm{MPa})$ & Young's modulus $(\mathrm{GPa})$ & Elongation at break (\%) \\
\hline Flax & 1.5 & $345-1.500$ & 27.6 & $2.7-3.2$ \\
\hline Jute & $1.3-1.49$ & $393-800$ & $13-26.5$ & $1.16-1.5$ \\
\hline Sisal & 1.45 & $468-700$ & $9.4-22$ & $3-7$ \\
\hline Hemp & 1.7 & 690 & 70 & 1.6 \\
\hline
\end{tabular}

inforced by [0-90 Woven Roving and Random] with volume fraction $25 \%$. The shore D hardness of all samples investigated before and after immersion in water at room temperature. Results of the work show that the value of hardness done at room temperature decreases with increasing the time of immersion in water.

Chandramohan [5] et al studied the effect of dry and wet conditions on tensile and hardness properties of bio-epoxy composites. In their research, natural fibers like Sisal (Agave sisalana), Banana (Musa sepientum) \& Roselle (Hibiscus sabdariffa), Sisal and banana (hybrid), Roselle and banana (hybrid) and Roselle and sisal (hybrid) are fabricated with bio epoxy resin using molding method. They studied flexural rigidity and hardness of Sisal and banana (hybrid), Roselle and banana (hybrid and Roselle and sisal (hybrid) composite at dry and wet conditions.

Dhakal et al. [6] studied the effect of water absorption on mechanical properties of hemp fiber reinforced of unsaturated polyester matrix composites. The composites specimens containing $0,0.10$, $0.15,0.21$ and 0.26 fiber volume fraction were prepared. Water absorption tests were conducted by immersing specimens in a de-ionized water bath at $25^{\circ} \mathrm{C}$ and $100{ }^{\circ} \mathrm{C}$ for different time durations. The percentage of moisture uptake increased as the fiber volume fraction increased due to the high cellulose content. They found that the tensile and flexural properties of composite specimens decrease with increase in percentage moisture uptake.

The knowledge of water and water vapor sorption in composites and in polymer matrices is considered to be of the most importance [3]. Therefore, it is important to study water absorption behavior in detail in order to evaluate not only the consequences that the water absorbed may have, but also how this water uptake can be minimized in some way.

The objective of this work was to compare the influence of both fiber reinforcement and water uptake on mechanical properties of flax fiber reinforcement epoxy composites and characteristics of the water absorption.

\section{MATERIALS AND METHOD}

\section{Materials}

The matrix material used in this study was based on a commercially available epoxy, Trade Name "MGS LR 160 (Hexion)" supplied by Dost Kimya Ltd. The matrix was mixed with curing catalyst, MGS LH 160 (Ep1kure) at a concentration of $0.40 \mathrm{w} / \mathrm{w}$ of the matrix for curing.

The reinforcement was a natural flax fiber (Fig. 1) bundle obtained by a biological retting process in which some waxes and pectin were removed. These fibers were kindly supplied by Vanes Ltd. For applications as composites reinforcement, fibers have to be separated individually to be homogeneously distributed.

The fibers prior to use were washed thoroughly with distilled water because fibers generally contain some impurities that may affect the bonding between the fibers and the polymer matrix. And then fibers dried in a vacuum oven (Ecocell 55 comport) at $130 \pm 2{ }^{\circ} \mathrm{C}$ for $24 \mathrm{~h}$.

\section{Specimen preparation}

All specimens in this study were manufactured by hand layup technique. The mould that was used in this work for casting process is made

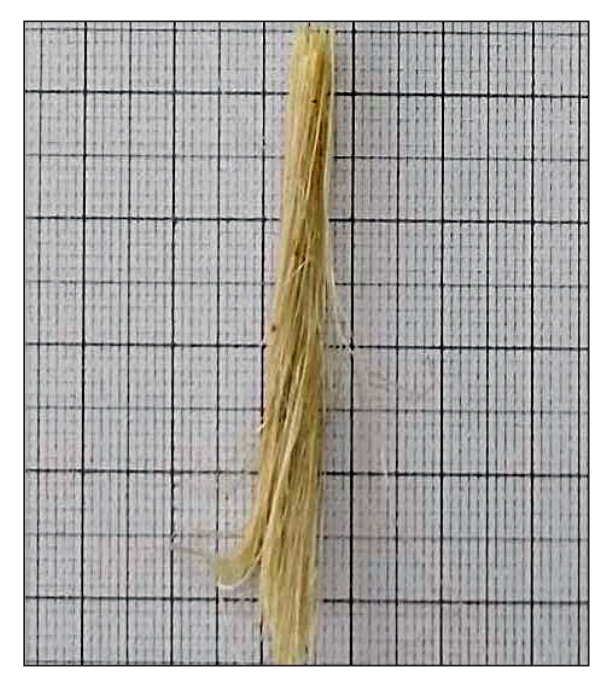

Fig. 1. Flax bundle 
of PMMA (Plexiglas) with dimension of (200, $200,10) \mathrm{mm}$ and it has cavities which shape of tensile and flexural test samples dimensions. The mould surface was allowed to dry after cleaning it with a thinner solution. After drying, the surface was coated with anti-adhesive agent. The polymeric material is prepared by mixing the epoxy resin with the hardener in $(100: 40)$ ratio at room temperature, the mixing was very slow, and using glass rod for (5 min) until it becomes homogenous. The flax bundle is added to the epoxy in different weight fractions of $(1,5,10) \%$ and continuously mixing until it becomes homogenous, the mixing is completed after ( $2 \mathrm{~min})$, then the mixture is poured into the mould. Figure 2 shows composite samples.

\section{Water absorption tests}

Water absorption studies were performed following the ASTM D 570-98 method (Memmert water bath). Water absorption of the composites was determined after $2 \mathrm{~h}$ and $24 \mathrm{~h}$ immersion in distilled water at $25^{\circ} \mathrm{C}$ and $90{ }^{\circ} \mathrm{C}$ (Fig. 3a). Five specimens of each formulation were dried in an oven (Fig. 3b) for $24 \mathrm{~h}$ at $103 \pm 2{ }^{\circ} \mathrm{C}$.

The dried specimens were weighed with a precision of $0.001 \mathrm{~g}$ (Sartorius ED 224S model) and were placed in distilled water. At the end of the immersion periods, the specimens were removed from the distilled water, the surface water was wiped off using blotting paper, and wet weight values were determined. Water absorption percent was calculated using the following formula:

$$
\mathrm{M}(\%)=\left(\mathrm{m}_{\mathrm{t}}-\mathrm{m}_{0}\right) / \mathrm{m}_{0} \times 100,
$$

where: $m_{0}$ and $m_{t}$ denote the oven-dry weight and weight after time $t$, respectively.

\section{Mechanical properties}

Tensile and flexural properties are the most commonly investigated mechanical properties of natural filler or synthetic filler reinforced plastic composites. In this study, both, tensile and flexural tests were performed using an Instron Univer-

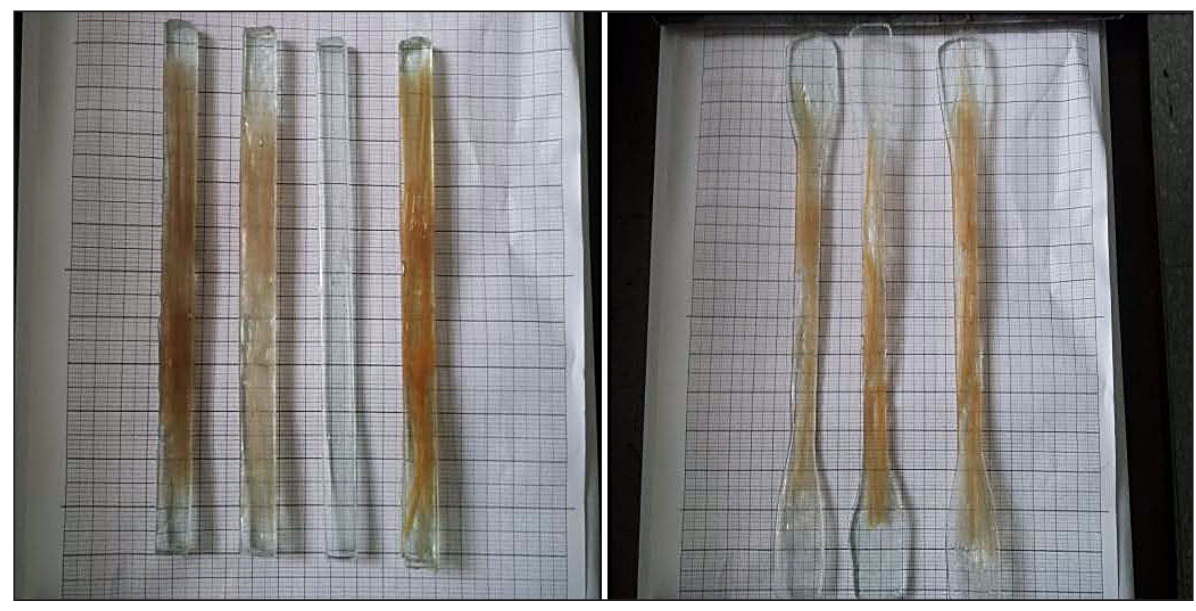

Fig. 2. Flexural and tensile test specimens

a)

b)

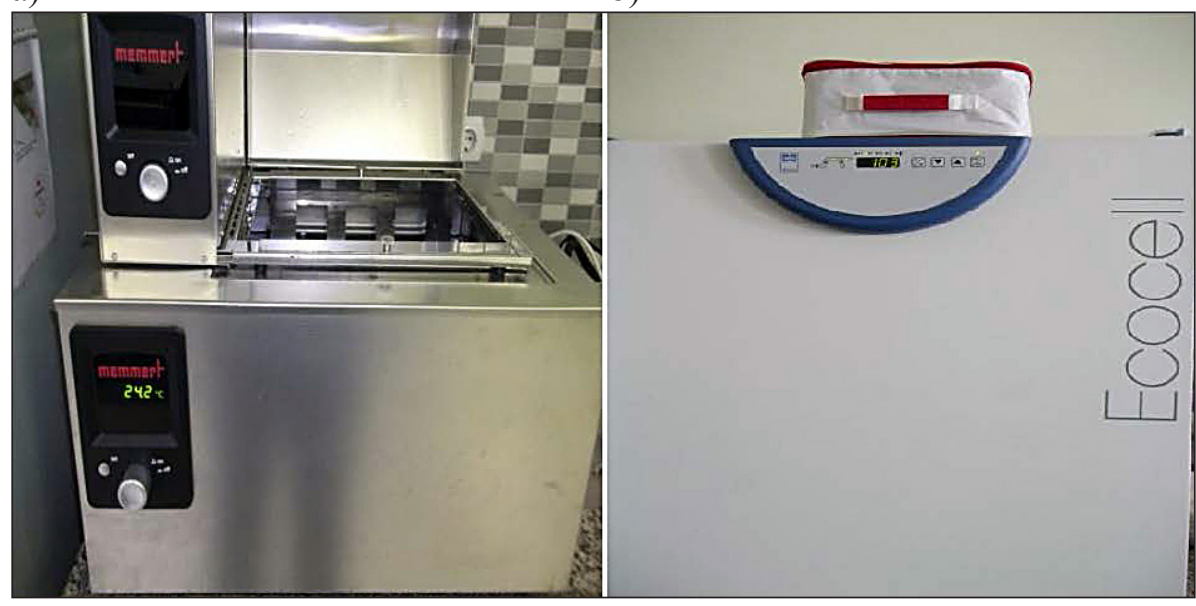

Fig. 3. a - water bath (left), b - drying oven (right) 
sal Testing Machine Model 8501, equipped with a $500 \mathrm{~kg}$ load cell, strain-gauge extensometer (Instron, model 2620) after conditioning at $23 \pm 2{ }^{\circ} \mathrm{C}$ according to ISO 527 standard and ASTM D790, respectively. The cross-head speed used for the type IA tensile specimens was $5 \mathrm{~mm} / \mathrm{min}$. For the Flexural test (three point bending) a specimen with nominal dimensions of $80 \times 10 \times 4 \mathrm{~mm}^{3}$, a span of $32 \mathrm{~mm}$ and a cross-head of $1 \mathrm{~mm} / \mathrm{min}$ were used.

\section{RESULTS AND DISCUSSION}

\section{Water absorption test results}

The effect of fiber loading on the water absorption flax fiber reinforced composites with increase in immersion time is shown in Figure 4. It is evident from the figure that the rate of moisture absorption increases with increase in fiber weight. The effect of fiber loading is concerned composites with $10 \mathrm{wt} \%$ flax fiber loading shows higher water absorption rate as compared to $5 \mathrm{wt} \%$ and $1 \mathrm{wt} \%$ fibers loading. The reason may be due to the flax fibers contain abundant polar hydroxide groups, which result in a high moisture absorption level of natural fiber reinforced polymer matrix composites.

Another effect of increasing water absorption rate of composites is the nature of flax fiber, voids inside the composites lead to the formation of micro channels. After a time immersion in water, the presence of these micro voids and cracks in the composite surface results in the movement of water molecules to the material by capillary action [7]

Figure $4 \mathrm{~b}$ shows that the absorption equilibrium was reached much faster at higher tempera-

a)

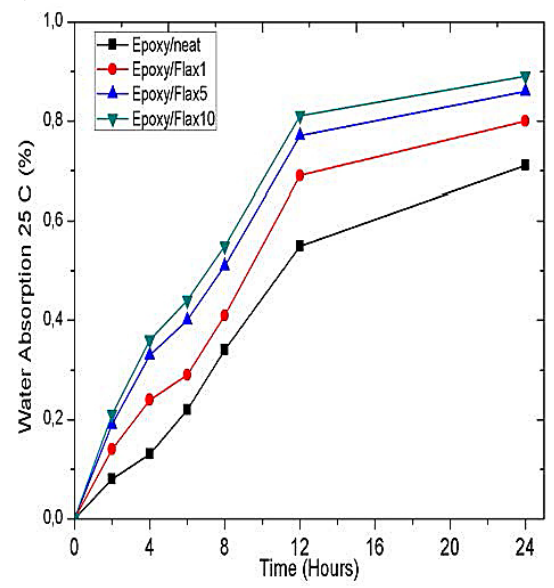

ture $(12 \mathrm{~h})$ and the amount of sorbed water was lower than that observed at $25^{\circ} \mathrm{C}$. According to the Le Chatalier's principle [3], the absorption process should be exothermal.

To have durable flax fibre reinforced composites, some significant studies have been conducted. Improving the poor environmental and dimensional stability of lignocellulosic materials is good to modify the tensile properties of flax fibres [8]. In the study by Stamboulis et al. [8], the environmental behavior of flax mat reinforced composites is investigated by monitoring the moisture absorption and swelling, and measuring the residual mechanical properties of the composites at different moisture levels. It confirmed that the moisture absorption and swelling of the Duralin treated flax composites is approximately $30 \%$ lower than that of the composites based on untreated flax fibres. Dhakal [6] found that hemp fiber reinforced polyester corresponding to 0 , $0.15,0.21$ and 0.26 fibre volume fractions, respectively, immersed at room temperature for 888 $\mathrm{h}$ is $0.879,5.63,8.16$ and $10.97 \%$, respectively. Water absorption value increased with increasing fiber loading. Similar results have been obtained in this study. This phenomenon can be explained by considering the water uptake characteristics of flax fibre. When the composite is exposed to moisture, the hydrophilic flax fibers swell. As a result of fibre swelling, micro cracking of the brittle thermosetting resin (like epoxy) occurs [6].

\section{Tensile and flexural test results}

The percentage of water absorption of the composites was evaluated as the difference between the initial and equilibrium absorption

b)

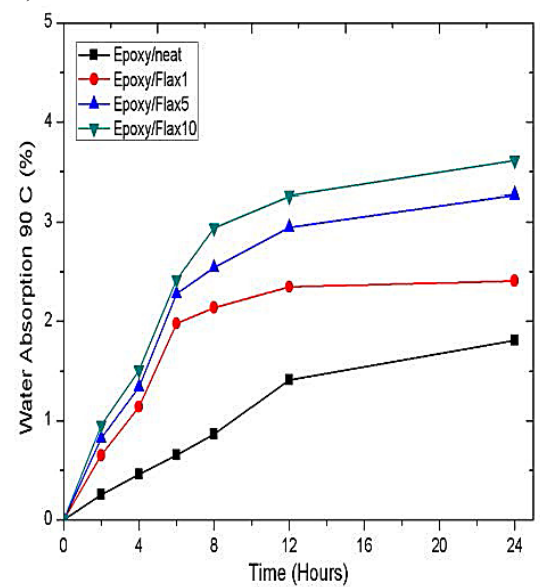

Fig. 4. $\mathrm{a}-25^{\circ} \mathrm{C}$ water absorption test results, $\mathrm{b}-90^{\circ} \mathrm{C}$ water absorption test results 
a)

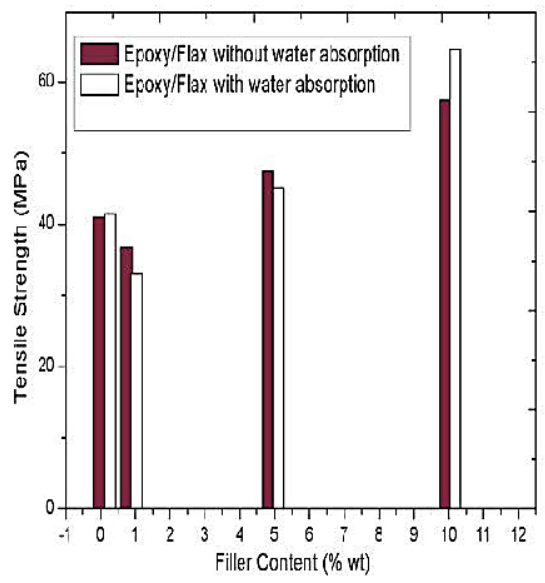

b)

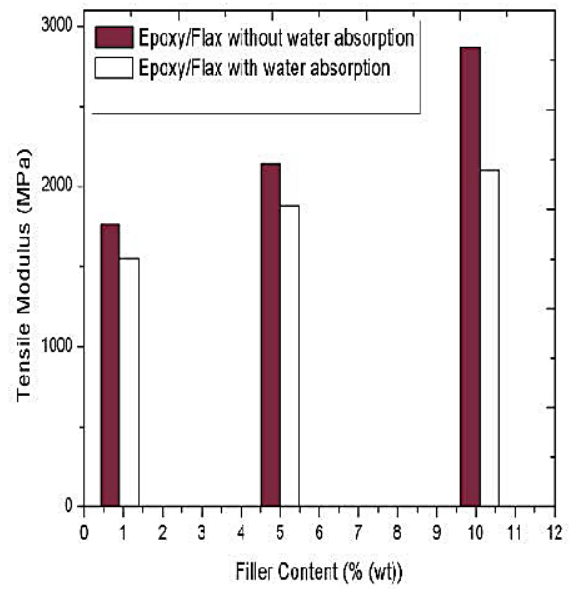

Fig. 5. a - tensile strength results with/without immersed water, $\mathrm{b}$ - tensile modulus results with/without immersed water $90{ }^{\circ} \mathrm{C}$

weights of the specimen. The influence of fiber loading on the tensile strength and tensile modulus of the composites is shown in Figures 5a and $5 \mathrm{~b}$ respectively.

Figure 5 shows that tensile strength of all specimens decreased with increasing water absorption rate. These results are because of water penetration inside polymers decreasing the connection between fiber and polymer material. Composite materials reinforced with flax fibers had many channels and capillary tube which allowed for water molecules to penetrate inside the materials and acting along the interface between epoxy and flax fiber causing swells in the samples. Then the bonds between resin and fibers will break. So the strength of the composite material will decrease. For the 10\% flax fiber reinforcing the ultimate tensile stress of wet samples is higher than that for dry samples. This could be due to the fact that high amounts of water causes swelling of the fibres, which could fill the gaps between the fibre and the polymer-matrix, and eventually could lead to an increase in the mechanical properties of the composites. Dhakal [6] et al has reported similar results in their research for hemp/polyester composites. The tensile stress drops by $38 \%$ in their study. Theoretically, high tensile strength of a natural fibre reinforced composite could be achieved by increasing the amount of the fibre used. Singleton et al. [9] investigated the effect of fibre volume fraction on the mechanical properties of flax mat/recycled HDPE composites by film stacking and compression moulding. It was observed that the tensile strength and modulus increased with an increase in fibre volume fraction $(0 \%, 10 \%, 18 \%, 20 \%$ and $30 \%)$.
Figure 5 shows the tensile properties of composites. All of the composites show higher tensile modulus than the neat epoxy resin. In particular, the tensile modulus strongly increases using as reinforcement $10 \% \mathrm{wt}$ of flax fibers. In particular, the $1 \%, 5 \%$ and $10 \%$ wt flax fiber composites show tensile modulus about 5\%,21\% and $71 \%$ higher than epoxy resin, respectively. Dhakal [6] et al. have reported the reduction in tensile modulus for 3, 4 and 5 layer hemp reinforced specimens compared to dry specimens is $61 \%, 97 \%$ and $87 \%$, respectively.

The simple tension and flexure modulus (Fig. 6) measurements can hence differ significantly when the material is inhomogeneous and anisotropic. A flexural test is highly influenced by the properties of the specimen closest to the top and bottom surfaces, whereas a simple tension test reflects the average property through the thickness [10]. In a flexural test, the total bending deflection is a combination of a bending deflection and a shear deflection as shown in Eq.:

$$
\delta=\mathrm{Pl}^{3} / 48 \mathrm{EI}+\mathrm{Pl} / 4 \mathrm{G} \text {. }
$$

The flexural stress (Fig. 6a) drops incrementally as the fibre volume fraction increases hence increased moisture uptake percentage. The decrease in flexural properties after water immersion can be related to the weak fibre-matrix interface due to water absorption.

The flexural modulus, however, is not adversely affected by moisture absorption. The increase in flexural modulus is more pronounced with higher fibre content specimens, hence higher moisture content. It would be intuitive to assume that the effect of fibre reinforcement to be less 
a)

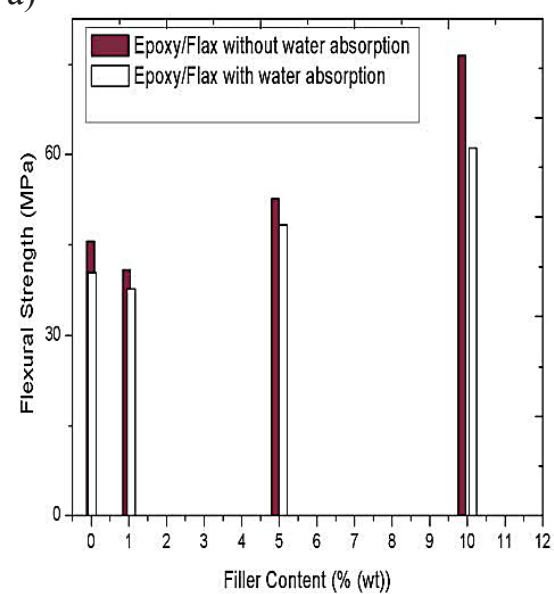

b)

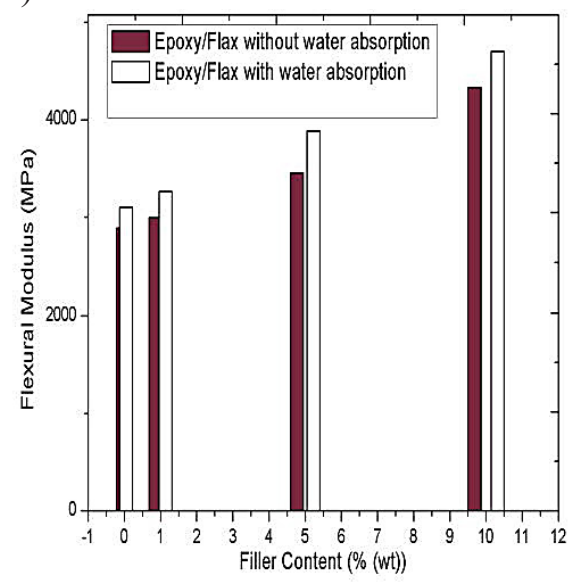

Fig. 6. a - flexural strength test results with/without immersed water, $\mathrm{b}$ - flexural modulus with/without immersed water $90^{\circ} \mathrm{C}$

critical for the flexural failure stress than in tensile failure mode. This is because the flexural samples fail in combination of compression, shear and tension mode [6].

\section{CONCLUSION}

Flax fibres are cost-effective materials have specific mechanical properties which have a potential to replace synthetic fibres as reinforcement in composite. Their main disadvantage is the variability in their properties. Environmental effects (e.g. high relative humidity) will degrade the tensile properties of flax fibres. A suitable chemical treatment (e.g. Silane, plasma) can increase the tensile strength and strain of the flax fibres.

\section{REFERENCES}

1. Baley C., Busnel F., Grohens Y., Sire O., Influence of chemical treatments on surface properties and adhesion of flax fibre-polyester resin. Composites. Part A. 37. 2006, 1626-1637.

2. Yan L., Chouw N., Jayaraman K., Flax fibre and its composites - a review. Composites, Part B, 56, 2014, 296-317.

3. Turmanova S., Dimitrova A., Vlaev L., Comparison of water absorption and mechanical behaviors of polypropylene composites filled with rice husks ash. Polymer-Plastics Technology and Engineering, 47, 2008, 809-818.

4. Faik H., Hind A., Hasan S., Effect of water absorption on hardness property for epoxy reinforced by glass fibers. Journal of University of Anbar for Pure Science, 5(3), 2011.

5. Chandramohan D., Marımuthu K., Tensile and hardness tests on natural fiber reinforced polymer composite material. IJAEST, 6, 2011, 97-104.

6. Dhakal H.N., Zhang Z.Y., Richardson M.O.W., Effect of water absorption on the mechanical properties of hemp fiber reinforced unsaturated polyester composites. Composites Science and Technology, 2006.

7. Narendar R., Priya Dasan K., Effect of chemical treatment on the mechanical and water absorption properties of coir pith/nylon/epoxy sandwich composites. International Journal of Polymer Anal. Charact., 18, 2013, 369-376.

8. Stamboulis A, Baillie C.A., Peijs T., Effects of environmental conditions on mechanical and physical properties of flax fibres, Composites, Part A, 32(8), 2001, 1105-1115.

9. Singleton A.C.N., Baillie C.A., Beaumont P.W.R., Peijs T., On the mechanical properties, deformation and fracture of a natural fibre/recycled polymer composite. Composites, Part B, 34(6), 2003, 519-526.

10. Wambua P., Ivens J., Verpoest I.. Natural fibres: can they replace glass in fibre reinforced plastics? Composites Science and Technology, 63, 2003, 1259-1264. 